\section{A safer technique for draining the bladder during flexible cystoscopy}

\author{
Kavit Amin, Wasim Mahmalji
}

Medway Maritime Hospital, UK

\begin{abstract}
We suggest a safer and more novel technique to performing suction drainage of the bladder during flexible cystoscopy.
\end{abstract}

\section{Technical Note}

Draining the bladder during flexible cystoscopy is routinely performed to examine the bladder and urinary system. It is used to aid both diagnoses and to monitor success of treatment. Biopsies can also be taken. The flexible cystoscope is passed through the urethra and into the bladder under direct vision. It is a thin fibre-optic telescope the width of a pen, which allows the operator to adjust the angle of the end of the scope (up to 180 degrees) to perform a more complete examination of the urinary system. The trigone, the lower part of the bladder is a smooth triangular opening between the urethra and bladder and is relatively more rigid than the flaccid upper fundus of the bladder. There are occasions when views are sub-optimal due to debris or the bladder needs to be filled with glycine after the instillation of saline (Such as taking bladder biopsies). The flexible cystoscope is prone to causing patient discomfort and irritation between the flaccid upper bladder wall and the flat end of the cystoscope. ${ }^{1}$ In our experience suction injuries can sometimes result in predisposition to infections and bleeding. There is also a serious risk of bladder perforation.

The authors believe this technique is a safer technique. We perform suction in the $J$ manoeuvre position with the distal end of the cystoscope close to the trigone. This allows the smooth edge of the scope to make contact with the bladder wall, thereby minimising patient discomfort and trauma to the bladder (Figure 1). Real-time visualization of the procedure and explanation of the procedure has been shown to decrease subjective pain scores. ${ }^{2}$ This may also be a valuable tip when performing flexible cystoscopy.

\section{References}

1. Wong LM, Huang JG, Yong TL, et al. Does sodium bicarbonate reduce painful voiding after flexible cystoscopy? A prospective, randomized, double-blind, controlled trial. BJU Int 2011;108:718-21.

2. Zhang ZS, Tang L, Wang XL, et al. Seeing is believing: a randomized controlled study
Correspondence: Kavit Amin, Medway Maritime Hospital, UK

E-mail: kavita299@doctors.org.uk

Key words: flexible cystoscopy, safer technique.

Received for publication: 7 August 2011.

Revision received: 26 October 2011.

Accepted for publication: 19 December 2012.

This work is licensed under a Creative Commons Attribution NonCommercial 3.0 License (CC BYNC 3.0).

(C) Copyright K. Amin and W. Mahmalji, 2012 Licensee PAGEPress, Italy

Surgical Techniques Development 2012; 2:e2 doi:10.4081/std.2012.e2

from China of real-time visualization of flexible cystoscopy to improve male patient comfort. J Endourol 2011;25:1343-6.

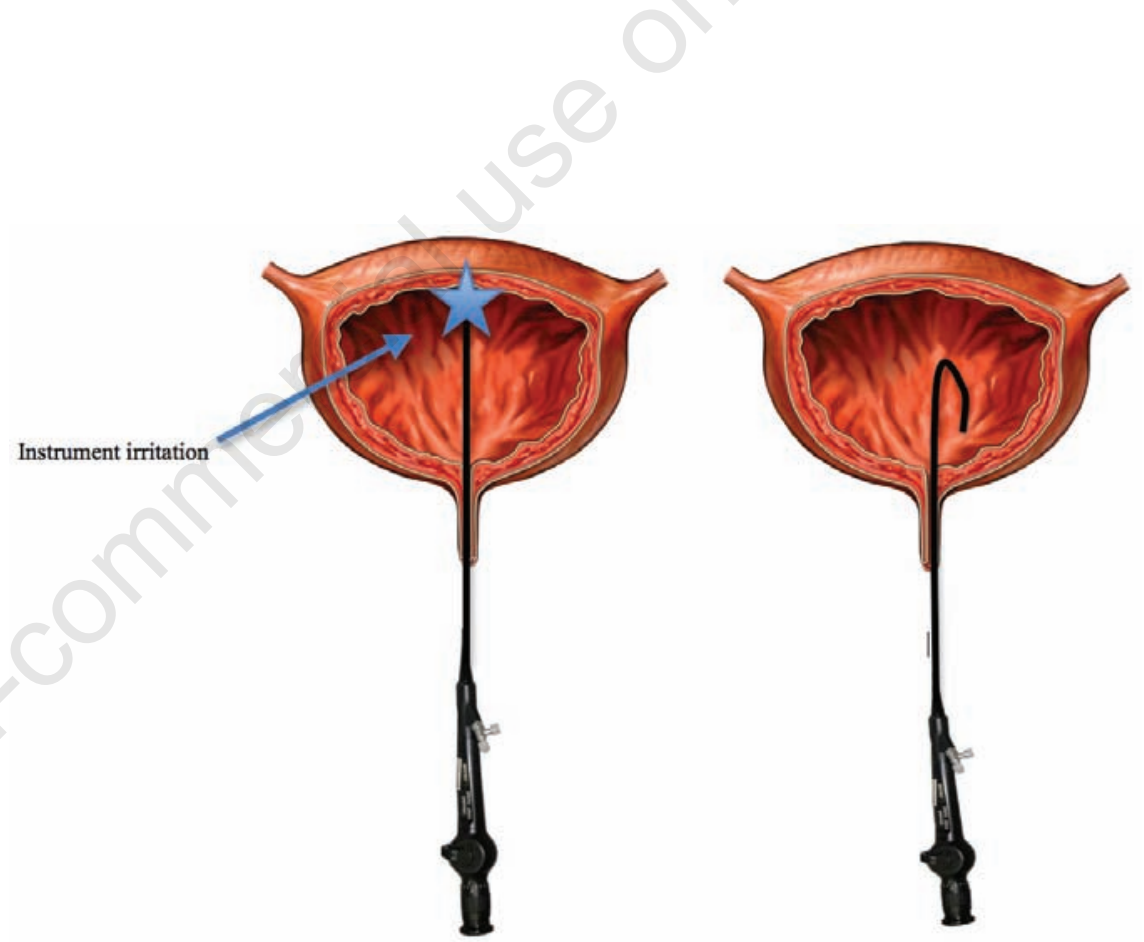

Figure 1. Safer technique for draining the bladder during flexible cystoscopy. 